\title{
Pregnant women's preferences for and concerns about preterm birth prevention: a cross-sectional survey
}

Vanessa $\mathrm{Ha}^{1 *}$ (D) and Sarah D. McDonald ${ }^{1,2,3}$

\begin{abstract}
Background: Although there is a call for patient-centred prenatal care, women's preferences for and concerns about preterm birth (PTB) prevention have not been well-studied. Therefore, we conducted a cross-sectional survey to determine women's preferences for PTB prevention and their likelihood of following their healthcare provider's recommendations for PTB prevention, as well as factors associated with these responses.

Methods: A piloted self-administered questionnaire was completed by pregnant women who could read English. Data were collected about their preferences for and concerns about PTB prevention, and the likelihood of following their healthcare provider's recommendations, using multivariable logistic regression to control for other factors.

Results: Three hundred and eleven women at a median of 32-weeks of gestation completed the survey, a response rate of $85.2 \%$. Most women reported that if they were told they were at increased risk for PTB, they preferred not to use PTB prevention (65.8\%), of whom almost all (93.4\%) reported they preferred close-monitoring and $6.6 \%$ preferred neither monitoring nor prevention. A much smaller proportion of women reported that they would not follow their healthcare provider's recommendation for progesterone (10.9\%) compared to pessary (28.7\%) or cerclage (50.2\%). Women who were neither married nor in a common-law relationship were more likely to report that they would not follow recommendations for progesterone ( $\mathrm{aOR}=5.88$ [95\% Cl: 1.72, 20.00]). Most women (84.5\%) reported they would use other sources of information other than their main healthcare provider to learn more about PTB prevention, with the most popular source being the internet.

Conclusions: Most women reported that if they were told they were at increased risk of PTB, they preferred closemonitoring over using PTB prevention. Their reported likelihood of not following their healthcare provider's recommendations for PTB prevention varied from $10.9 \%$ for progesterone to $50.2 \%$ for cerclage. These findings suggest that more education about the risk of PTB, PTB preventions, as well as compliance with progesterone is needed and that the internet would be an important source of information. However as our study was completed by women at a median of 32 weeks of gestation, future surveys targeted at women earlier in their pregnancy are needed.
\end{abstract}

Keywords: Preterm birth prevention, Patient preference, Survey, Progesterone, Cerclage, Pessary

\footnotetext{
* Correspondence: hav3@mcmaster.ca

${ }^{1}$ Department of Health Research Methods, Evidence, and Impact, McMaster University, Hamilton, ON, Canada

Full list of author information is available at the end of the article
}

\section{Ciömed Central}

(c) The Author(s). 2017 Open Access This article is distributed under the terms of the Creative Commons Attribution 4.0 International License (http://creativecommons.org/licenses/by/4.0/), which permits unrestricted use, distribution, and reproduction in any medium, provided you give appropriate credit to the original author(s) and the source, provide a link to the Creative Commons license, and indicate if changes were made. The Creative Commons Public Domain Dedication waiver (http://creativecommons.org/publicdomain/zero/1.0/) applies to the data made available in this article, unless otherwise stated. 


\section{Background}

Preterm birth (PTB) is a serious public health concern. It is the leading cause of perinatal mortality in Canada [1] and is also associated with an increased risk of neonatal death [2]. Beyond its contribution to mortality, PTB can have lifelong effects on neurodevelopmental functioning through cerebral palsy, impaired learning, and visual disorders [3]. The maternal psychological cost is also high as many women experience anxiety and stress over the immediate and long-term health consequences for their preterm infant [4].

Interventions to reduce the risk for PTB include progesterone [5], cerclage [6, 7], and pessary [8]. Most of these studies have been conducted in women with a short cervix and/or a previous spontaneous PTB [5-7]. Furthermore, to date, studies have not found one prevention to be most effective in reducing PTB risk $[9,10]$. The uncertainty over the best prevention is reflected in guidelines which note the limited evidence to support progesterone [11] and cerclage uses [12]. In the absence of clear guidelines, the decision to use PTB prevention is mostly left up to women and their healthcare providers. Given that $56.2 \%$ of women who eventually have PTB do not have traditional PTB risk factors [13], studying the acceptability of PTB prevention and identifying preferences and concerns that can be addressed during counselling is important.

Moreover, although there is a call for patient-centred prenatal care [14], women's preferences for and concerns about PTB prevention have not been well-studied. A previous cross-sectional survey [15] and two chart review studies $[16,17]$ focused on the acceptability of and concerns about progesterone. We identified one healthcare provider survey on cerclage [18], but most studies have focused on counselling practices on progesterone $[15,18-24]$. The need to consider women's preferences is important because evidence has shown that most women reported greater satisfaction with their pregnancy when they were actively involved in medical decisions [25], and satisfaction, in turn, has been linked to increased confidence in their ability to take better care of themselves and their infants [26]. Despite this importance, there has been no study to date conducted in women to understand their preferences for and concerns about PTB prevention overall.

To help address this important gap, we designed a survey, informed by previous studies [15] to understand women's preferences for and concerns about PTB prevention including progesterone, cerclage, and pessary.

\section{Methods}

The design of our survey followed Dillman's Method [27] and the reporting of results was informed by Kelley et al. [28].

\section{Recruitment}

The study sample included women from obstetric clinics and midwifery clinics in Southwestern Ontario, Canada. Between November 2015 and February 2016, clinic staff mentioned the survey to all potentially eligible women. Interested women were referred to research personnel (V.H.), who described the purpose of the survey and distributed the hard copies of the questionnaire. Consent to participate was indicated by completion and submission of the questionnaire. The Hamilton Health Sciences/ McMaster University granted Research Ethics Board approval for study prior to commencement (Reference Number: 2015-0459-GRA).

\section{Eligibility Criteria}

Pregnant women who could read English sufficiently well were eligible to participate. Because greater than $56.2 \%$ of women who experience PTB do not present with traditional risk factors [13], we included all women, not only those identified as having increased risk of PTB.

\section{Questionnaire}

To inform the design of our questionnaire, the first to our knowledge, to study women's preferences for and concerns about PTB prevention including progesterone, cerclage, and pessary, three electronic databases (MEDLINE, EMBASE, and CINAHL) were searched up until April 2015 to identify previous surveys on PTB prevention. One previous survey that used an invalidated questionnaire to ask women about their preferences for progesterone therapy was identified [15]. We used the findings of this previous study to inform the development of our questionnaire.

Our questionnaire gathered information on: 1) sociodemographics, 2) past and current pregnancies, 3) preferences for and concerns about each of the three PTB preventions, 4) likelihood of following their healthcare provider's recommendation for each of the PTB preventions and 5) sources of information that women would seek to learn more about PTB prevention (see Additional File 1). Questions were a mix of five-point Likert scales, open-ended, and semi-closed ended questions. The questionnaire was piloted for comprehensibility of questions and answers and for flow in three women of child-bearing age and was revised accordingly.

\section{Outcomes}

Our primary outcome was the preference not to use PTB prevention if women were told they were at increased risk for PTB. Secondary outcomes included the proportion of women who reported they would not follow their healthcare provider's recommendation for PTB prevention and associated factors. 


\section{Sample size calculation}

To provide a precise estimate for our primary outcome, we used a one proportion calculation formula to determine our sample size: $\mathrm{n}=\mathrm{p}(1-\mathrm{p})(1.96 / \mathrm{m})^{2}$, where $n$ is the sample size, $p$ is the estimated proportion, and $m$ is the margin of error. Because we were unsure of the proportion of women who would prefer any PTB prevention, we assumed that $p=0.50$. For this estimated proportion, we found that the formula provided the largest sample size when $m=0.06$. Thus, we conservatively estimated that we needed to recruit 310 respondents for our survey with a missing data rate of $15 \%$.

\section{Statistical Analysis}

Responses from completed questionnaires were entered into LimeSurvey (Version 1.91+ Build 120302) for data management. Data were analyzed using SAS 9.4 (SAS Institute Inc, Cary, North Carolina). Normally distributed continuous variables were calculated as means with standard deviations (SD) and non-normally distributed continuous variables were calculated as medians with their interquartile ranges (IQR). Categorical variables were described as counts and percentages. Continuous variables were tested for significance using the independent $t$-test or MannWhitney-Wilcoxon test and categorical variables were tested using Fisher's Exact or chi-squared tests. A threshold of $\mathrm{p} \leq 0.05$ was used to determine statistical significance.

Multivariable logistic regression was conducted for our primary and secondary outcomes, and the results are reported as adjusted odds ratios (aOR) with 95\% confidence intervals (CIs). To select variables for our multivariable logistic regression, we considered a priori biologically plausible variables performed with a $\mathrm{p}$-value for entry in a stepwise regression set at 0.10 and p-value for stay set at 0.20 . A priori chosen variables included age, ethnicity, education, relationship status, type of healthcare provider whom women selected for prenatal care, smoking status, PTB risk status for the current pregnancy, gestational week at the time the questionnaire was completed, concerns about PTB preventions, and in the case of the secondary outcome, preference to not use PTB prevention. Multicollinearity was assessed using variance inflation factor (VIF), where a VIF less than or equal to five was considered to be evidence of multicollinearity. If multicollinearity was detected, the variable with the most biological plausibility was kept or if biological plausibility between variables were considered equal, the variable with the greater number of responses was kept. Only participants who provided a response to every question in the questionnaire was included in the multivariable logistic model for analysis (i.e. complete-case analysis).

For our primary outcome, women were asked to "imagine a scenario in which their healthcare provider thought they were at increased risk of premature or early birth" and then to indicate which of the following types of management they would prefer. Based on their responses, we grouped women who responded with a preference for one or more of the three PTB preventions (progesterone, cerclage, pessary) as having a "preference to use prevention" while women who responded with a preference for close-monitoring only or preference for no prevention at all as having a "preference to not use prevention." For our secondary outcome, women were asked to indicate "how likely or unlikely they would be to follow their healthcare provider's recommendation if their main healthcare provider had recommended the following preventions?" Taking a similar approach as our primary outcome, women who reported that they were "not likely" or "slightly unlikely" to follow healthcare provider's recommendation on a 5-point Likert scale were categorized as those who "reported they would not follow the recommendation" and women who reported that they were "neutral," "slightly likely," or "extremely likely" as those who "reported neutral or would follow recommendation."

\section{Results \\ Recruitment results}

Of the 365 pregnant women who were eligible, 311 women completed the survey, a response rate of $85.2 \%$. One woman was excluded as she had had $>50 \%$ incomplete data. The average missing data rate per question was $1.4 \%$.

\section{Characteristics of survey respondents}

Respondents had a mean age of 30.9 years and selfidentified predominantly as European/White-Caucasian (82.1\%, Table 1). Most women were married or in a common-law relationship (94.5\%), and had received at least some post-secondary education (84.5\%). A small proportion currently smoked (7.4\%). The median gestational age at the time the questionnaire was completed was 32.0 weeks (IQR: 26.7- 35.7 weeks). Most women had had a previous pregnancy (61.5\%), of whom 25 (13.2\%) reported that they had had a PTB. Thirteen (4.2\%) pregnant women have been told by their healthcare provider that their current pregnancy was at increased risk for PTB, of whom 10 had received a cervical assessment by ultrasound only (76.9\%), one received a cervical assessment by ultrasound and progesterone $(7.7 \%)$, one was instructed to do light physical activity $(7.7 \%)$, and one did not report receiving an ultrasound or advice (7.7\%). Respondents reported receiving most of their prenatal care from obstetricians (44.4\%), midwives (33.8\%), and family doctors (17.4\%). 
Table 1 Characteristics of the study sample of survey respondents

\begin{tabular}{ll}
\hline Variable & $\begin{array}{l}\text { Response, } n \\
(\%)^{\mathrm{a}}\end{array}$ \\
\hline $\begin{array}{l}\text { Pregnant Women's Characteristics } \\
\text { Age (years), mean } \pm \text { SD }\end{array}$ & $30.9(5.4)$ \\
Gestational age (weeks), median (interquartile range) & $32.0(26.7$, \\
& $35.7)$ \\
European/White-Caucasian (self-reported) & $252(82.1)$ \\
Married or in a common-law relationship & $292(94.5)$ \\
Education & \\
$\quad$ Secondary school or less & $48(15.5)$ \\
$\quad$ Post-secondary school & $262(84.5)$ \\
Current smokers & $23(7.4)$ \\
Obstetric History & \\
Prior miscarriage & $28(14.7)$ \\
Prior full-term birth ( $\geq 37$ weeks) & $150(48.5)$ \\
Prior preterm birth (<37 weeks) & $25(13.2)$ \\
$\quad$ Received progesterone & $2(8.0)$ \\
Advised to rest in bed (bedrest) & $1(4.0)$ \\
Current Pregnancy Characteristics & \\
First-time pregnancy & $119(38.5)$ \\
Told by healthcare provider that they were at increased & $13(4.2)$ \\
risk for preterm birth & $10(76.9)$ \\
Received ultrasound & $1(7.7)$ \\
\hline Received ultrasound + progesterone & \\
\hline a $~$ &
\end{tabular}

${ }^{\mathrm{a}} \mathrm{N}=311$ respondents completed the survey

\section{Preference for PTB prevention}

Most women (65.8\%) reported that if their healthcare provider told them they were at increased risk for PTB, they would prefer not to use any prevention; of whom 185 (93.4\%) women preferred close-monitoring only and $13(6.6 \%)$ women preferred no prevention at all including close-monitoring (Table 2). Of those who did report a preference for prevention, 53 (60.2\%) women reported they preferred to use one type of prevention to manage their PTB risk and 25 (24.3\%) women reported they preferred to use all three preventions. Progesterone was the most frequently chosen choice amongst women who preferred to use one type of prevention (84.9\%) and amongst women who preferred to use two preventions (94.4\%). Our univariate and multivariate logistic regression did not identify any significant factors associated with a preference to not use PTB prevention.

Almost all women rated concerns about effectiveness of the three preventions or the potential harm caused by them to the infant or themselves as "slightly important" or "extremely important", on a Likert scale ranging from "extremely unimportant" to "extremely important"
(Table 3). In contrast, the cost of progesterone was not viewed as being of high importance to most women.

\section{Likelihood of following healthcare provider's recommendation for PTB prevention}

The highest proportion of women reported they would not follow their healthcare provider's recommendation was for cerclage $(50.2 \%)$, followed by pessary $(28.7 \%)$ and then progesterone (10.9\%). (Table 4 )

Women who were not married or in a common-law relationship were significantly more likely to report they would not follow recommendations for progesterone $(\mathrm{aOR}=5.88$ [95\% CIs: $1.72,20.00] ; \mathrm{p}=0.0049$, Table 5) than women who are married or in a common-law relationship. In addition, women who preferred not to use prevention were more likely to report they would not follow recommendations for cerclage $(\mathrm{aOR}=3.39[95 \%$ CI: $1.93,5.96] ; \mathrm{p}<0.0001)$ or pessary $(\mathrm{aOR}=2.99[95 \%$ CI: $1.51,5.92] ; \mathrm{p}=0.002$ ).

\section{Sources of information on PTB prevention}

Two hundred sixty-two women (84.5\%) reported they would use other sources of information other than their main healthcare provider to help them make their decisions to use PTB prevention. The top four information sources that women reported they would use were the internet (70.9\%), family and friends (55.5\%), other healthcare providers $(40.0 \%)$, and books or scientific literature $(38.1 \%)$.

\section{Discussion}

This was the first survey to our knowledge conducted to study the preferences for and concerns about current options for preterm prevention in pregnant women. Most women reported that they preferred not to use prevention but preferred close-monitoring of their pregnancy if they were told by their healthcare provider they were at increased risk for PTB. Approximately 50.2\% and $28.7 \%$ of women reported that they would not follow their healthcare provider's recommendations for cerclage and pessary, respectively, but only $10.9 \%$ did for progesterone. These findings were surprising because we had hypothesized that pessary would be more attractive than progesterone to many women and since previous surveys have reported a high acceptance rate for PTB prevention with progesterone among women who had been identified to be at increased risk of PTB [15-17].

There are a few reasons which might explain why most women preferred not to use prevention if they had been told by their healthcare provider they were at increased risk of PTB. Although it may relate to the hypothetical nature of the scenario, it may also reflect respondents' lack of understanding about the risks of preterm birth, which points to important opportunities 
Table 2 Comparison of the characteristics between women who preferred no prevention vs women who preferred at least one prevention

\begin{tabular}{|c|c|c|c|}
\hline Variables $^{a}$ & $\begin{array}{l}\text { Preferred no prevention }{ }^{\mathrm{b}}, \\
(n=198)\end{array}$ & $\begin{array}{l}\text { Preferred prevention }{ }^{c} \\
(n=103)\end{array}$ & $p$-value for difference ${ }^{d}$ \\
\hline \multicolumn{4}{|l|}{ Pregnant Women's Characteristics } \\
\hline Age (years), mean $\pm S D$ & $30.7(5.6)$ & $31.0(5.1)$ & 0.64 \\
\hline European or White-Caucasian ethnicity (self-reported) & $167(85.6)$ & $90(88.2)$ & 0.59 \\
\hline Post-secondary education & $164(82.8)$ & $90(87.4)$ & 0.32 \\
\hline Married or in common-law relationship & $185(93.9)$ & $99(96.1)$ & 0.59 \\
\hline Current Smokers & $14(7.1)$ & $8(7.8)$ & 0.82 \\
\hline \multicolumn{4}{|l|}{ Primary Healthcare Provider } \\
\hline Obstetrician & $87(43.9)$ & $49(47.1)$ & 0.42 \\
\hline Family physician & $62(31.3)$ & 37 (35.6) & \\
\hline Midwife & $40(20.2)$ & $13(12.5)$ & \\
\hline Others $^{\mathrm{e}}$ & $9(4.6)$ & $5(4.8)$ & \\
\hline \multicolumn{4}{|l|}{ Obstetric History } \\
\hline Prior full-term birth & $95(79.8)$ & $51(76.1)$ & 0.58 \\
\hline Prior preterm birth & $14(11.8)$ & $11(16.2)$ & 0.50 \\
\hline Prior use of preterm birth prevention & $2(14.3)$ & $1(9.1)$ & 1.00 \\
\hline Received progesterone & $0(0.0)$ & $1(50.0)$ & 1.00 \\
\hline Advised to rest in bed (bedrest) & $1(100.0)$ & $1(50.0)$ & 1.00 \\
\hline \multicolumn{4}{|l|}{ Current Pregnancy Characteristics } \\
\hline Gestational age at point of survey completion (weeks), mean \pm SD ${ }^{f}$ & $31.0(7.6)$ & $29.6(7.5)$ & 0.12 \\
\hline At increased risk for preterm birth & $12(6.1)$ & $1(1.0)$ & 0.04 \\
\hline \multicolumn{4}{|l|}{ Preterm Birth Prevention Preferences } \\
\hline Preferred no close-monitoring nor prevention & $13(6.6)$ & & \\
\hline Preferred close-monitoring only & $185(93.4)$ & & \\
\hline Preferred close-monitoring and prevention & & $15(14.6)$ & \\
\hline Preferred progesterone only & & $13(86.7)$ & \\
\hline Preferred cerclage only & & $1(6.7)$ & \\
\hline Preferred all 3 preventions & & $1(6.7)$ & \\
\hline Preferred preterm birth prevention only & & $88(85.4)$ & \\
\hline Selected 1 prevention only & & $53(60.2)$ & \\
\hline Progesterone only & & $45(84.9)$ & \\
\hline Cerclage only & & $5(9.4)$ & \\
\hline Pessary only & & $3(5.7)$ & \\
\hline Selected 2 preventions & & $18(20.4)$ & \\
\hline Progesterone + Cerclage & & $8(44.4)$ & \\
\hline Progesterone + Pessary & & $9(50.0)$ & \\
\hline Cerclage + Pessary & & $1(5.6)$ & \\
\hline Selected all 3 preventions & & $25(24.3)$ & \\
\hline
\end{tabular}

${ }^{a}$ Data is expressed as $\mathrm{n}(\%)$ unless otherwise specified

"Preferred no prevention" included women who preferred no prevention, close-monitoring only, or were not using a prevention if they were at increased risk for preterm birth

c"Preferred prevention" included women who preferred a prevention, close-monitoring and a prevention, or were using a prevention if they were at increased risk for preterm birth

${ }^{\mathrm{d}}$ Significance was assessed using independent $t$-test for continuous variables and chi-squared test or Fisher's exact test for categorical variables;

eOthers included Maternal-Foetal Medicine Specialists, Nurses, and Fertility Specialists

f Mann-Whitney-Wilcoxon test was used to test for significance 
Table 3 Importance of various concerns about preterm birth prevention

\begin{tabular}{|c|c|c|c|c|c|c|}
\hline Issue & $\begin{array}{l}\text { Number of } \\
\text { responses, } n\end{array}$ & $\begin{array}{l}\text { Not at all } \\
\text { important, } n(\%)\end{array}$ & $\begin{array}{l}\text { Slightly not } \\
\text { important, } n(\%)\end{array}$ & $\begin{array}{l}\text { Neutral, } \\
n(\%)\end{array}$ & $\begin{array}{l}\text { Slightly } \\
\text { important, } n(\%)\end{array}$ & $\begin{array}{l}\text { Extremely } \\
\text { important,n (\%) }\end{array}$ \\
\hline \multicolumn{7}{|l|}{$\begin{array}{l}\text { Potential Harm } \\
\text { Caused to Baby }\end{array}$} \\
\hline Progesterone & 309 & $1(0.3)$ & $1(0.3)$ & $7(2.3)$ & $8(2.6)$ & $292(94.5)$ \\
\hline Cerclage & 306 & $2(0.6)$ & $2(0.6)$ & $4(1.3)$ & $9(2.9)$ & $289(94.4)$ \\
\hline Pessary & 307 & $2(0.6)$ & $2(0.6)$ & $9(2.9)$ & $9(2.9)$ & 285 (92.8) \\
\hline \multicolumn{7}{|l|}{$\begin{array}{l}\text { Potential Harm } \\
\text { Caused to Mother }\end{array}$} \\
\hline Progesterone & 309 & $4(1.3)$ & $6(1.9)$ & $20(6.5)$ & $86(27.8)$ & $193(62.5)$ \\
\hline Cerclage & 306 & $5(1.6)$ & $5(1.6)$ & $14(4.6)$ & 60 (19.6) & $222(72.5)$ \\
\hline Pessary & 307 & $3(1.0)$ & $5(1.6)$ & $18(5.9)$ & $71(23.1)$ & $210(68.4)$ \\
\hline \multicolumn{7}{|l|}{$\begin{array}{l}\text { Effectiveness of } \\
\text { Prevention }\end{array}$} \\
\hline Progesterone & 309 & $1(0.3)$ & $4(1.3)$ & $29(9.4)$ & $67(21.7)$ & $239(78.1)$ \\
\hline Cerclage & 306 & $2(0.6)$ & $3(1.0)$ & $22(7.2)$ & $40(13.1)$ & $239(78.1)$ \\
\hline Pessary & 307 & $2(0.6)$ & $3(1.0)$ & $26(8.5)$ & $52(16.9)$ & $224(73.0)$ \\
\hline \multicolumn{7}{|l|}{$\begin{array}{l}\text { Associated } \\
\text { Financial Cost }\end{array}$} \\
\hline Progesterone & 309 & $92(29.8)$ & $38(12.3)$ & $75(24.3)$ & $65(21.0)$ & 39 (12.6) \\
\hline
\end{tabular}

for education. Alternatively, healthcare providers' satisfaction with their knowledge and confidence in the quality of evidence for progesterone have been associated with its prescription [24]. Interestingly, patient characteristics do not consistently elicit its prescription, even for women visiting the same clinic $[14,24]$. Other studies also reported that there is significant variation in clinical practice in progesterone for PTB prevention even amongst those working in the same clinic serving women with high-risk pregnancies [14, 16-18]. However, two surveys found that most healthcare providers would be willing to take part in hypothetical progesterone trials to further evaluate its effects on PTB prevention [21, 29]. Taken together these studies suggest that the behaviour of healthcare providers may play an important role in women's decision to use PTB prevention and healthcare provider's preferences for and concerns about PTB prevention need to be studied to better understand how their thought processes may influence their clinical practice.

The reluctance to follow recommendations for preventions that are more intrusive may be due to concerns about complications. In addition, we found that women who were not married or in a common-law relationship were more likely to report that they would not follow recommendations for progesterone. Marriage may be a proxy for social support [30] and less immediate social support may impact decision making. Previous studies have reported that women who are not married were more likely to start prenatal care later and have fewer prenatal visits [31] and in turn, women who receive less prenatal care have been associated with lower selfesteem and confidence [32]. Providing additional support or resources might be particularly important to this group of women, hence suggesting reputable online information sources would likely be beneficial.

Strengths of our study include a diverse sample of women from a broad range of healthcare providers including obstetricians, midwives and family physicians. Second, the response rate of our survey of $85.2 \%$ is robust, thus reducing the potential impact of selection bias. Third, our questionnaire was piloted, which likely increased read-ability. Finally, we used previous surveys that studied the preferences and values for PTB prevention to inform the design of our questionnaire [15].

Limitations of our study include that most women were relatively well educated, therefore, our results can only be understood in this context. Women who are more educated may prefer active participation in medical decisions [33] and are less likely to rely solely on the expertise of their healthcare providers for information. Further, because women in our sample were at a median of 32 weeks of gestation, they may prefer not to use PTB prevention because they were in the third trimester, and unaware of the risks of giving birth at this point in the pregnancy. Future surveys should consider women earlier in their pregnancy. Second, most women who responded to our survey were not at increased-risk for PTB. 


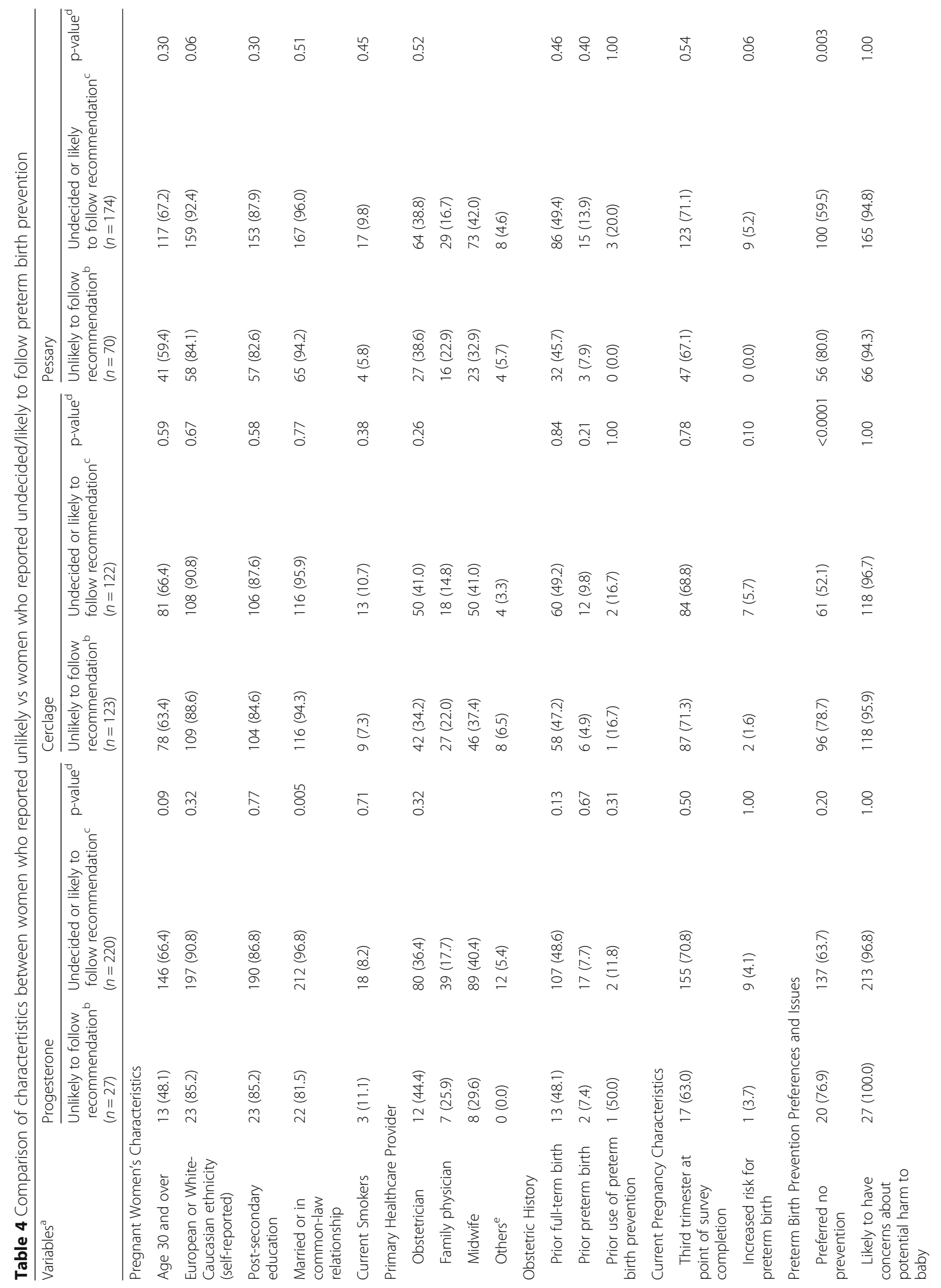




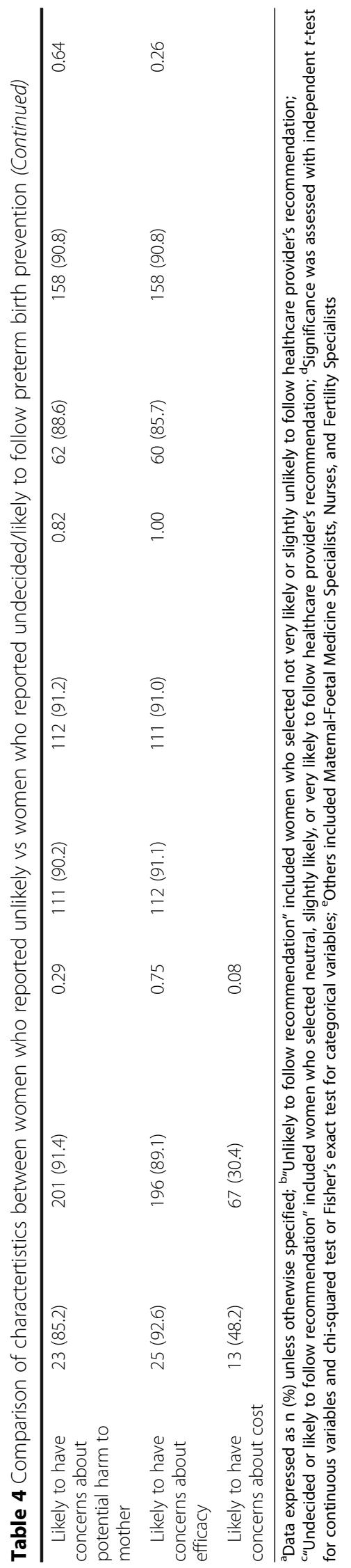


Table 5 Multivariate logistic regression of the likelihood of not following healthcare provider's recommendation

\begin{tabular}{|c|c|c|c|c|c|c|}
\hline \multirow[t]{2}{*}{ Variables $^{a}$} & \multicolumn{2}{|l|}{ Progesterone } & \multicolumn{2}{|l|}{ Cerclage } & \multicolumn{2}{|l|}{ Pessary } \\
\hline & $\begin{array}{l}\text { Multivariate } \\
\text { Analysis OR (95\% Cls) }\end{array}$ & $p$-value ${ }^{b}$ & $\begin{array}{l}\text { Multivariate } \\
\text { Analysis OR }(95 \% \mathrm{Cls})\end{array}$ & $p$-value ${ }^{b}$ & $\begin{array}{l}\text { Multivariate } \\
\text { Analysis OR (95\% Cls) }\end{array}$ & $p$-value \\
\hline \multicolumn{7}{|l|}{ Pregnant Women's Characteristics } \\
\hline $\begin{array}{l}\text { European or White-Caucasian ethnicity } \\
\text { (self-reported) }\end{array}$ & & & & & $0.41(0.17,1.01)$ & 0.05 \\
\hline Not married or in common-law relationship & $5.88(1.72,20.00)$ & 0.0049 & & & & \\
\hline \multicolumn{7}{|l|}{ Preterm Birth Prevention Issues ${ }^{c}$} \\
\hline Preference for no prevention & & & $3.39(1.93,5.96)$ & $<0.0001$ & $2.99(1.51,5.92)$ & 0.002 \\
\hline
\end{tabular}

Abbreviations: $\mathrm{OR}$, odds ratio; $\mathrm{Cl}$, confidence intervals. " "Preferred no prevention" included women who preferred no prevention or close-monitoring or were not using a prevention if they were at increased risk for preterm birth; ${ }^{\text {b }}$ Significance was assessed using chi-squared test

Hypothetical scenarios represent abstractions of reallife phenomena and women who are not at increased risk for PTB may answer differently if they were actually at increased risk. However, it is also possible that because our questionnaire offers anonymity and confidentiality, women may be more likely to answer their actual preferences for PTB prevention. Previous studies have found that almost one-fifth of women using progesterone to manage risk of PTB report issues of compliance [17]. More research needs to be conducted around patient compliance with treatment.

\section{Conclusions}

Our findings have implications for women's prenatal care. We found that most women preferred not to use PTB prevention but still preferred closemonitoring of their pregnancy if they were told by their healthcare provider they were at increased risk for PTB. A sizeable portion of women reported that they would not follow their healthcare provider's recommendations for cerclage and pessary, respectively, hence, providing additional education to women requiring such interventions would be particularly important. Since the complications of PTB can be severe and long-lasting, it is important to provide high quality education to women about PTB and the benefits associated with PTB prevention, including through websites as $70 \%$ of women in our survey reported they would use the internet to learn more about PTB prevention. Written or online information could help supplement the education provided by healthcare providers, which is important as a previous study had reported poor recall concordance between physicians and parents on key factors like potential neonatal complications resulting from PTB [34]. Further, because of the importance of healthcare providers influence on prenatal care, there is a need to better understand the healthcare providers' knowledge of, preferences for, and concerns about PTB prevention.

\section{Additional file}

Additional file 1: Questionnaire adminstered to women to assess their thoughts about and preferences for PTB prevention. (PDF $578 \mathrm{~kb}$ )

\section{Abbreviations}

aOR: Adjusted odds ratios; Cls: Confidence intervals; IQR: Interquartile ranges; m: Margin of error; n: Sample size; p: Estimated proportion; PTB: Preterm birth; SD: Standard deviation; VIF: Variance inflation factor

\section{Acknowledgement}

We thank the women who shared their opinions with us, the staff at the participating prenatal clinics: Dr. Aseel Hamoudi, Dr. Dustin Costescu, Dr. Ann Marie Chen, Dr. Carmela Sciarra, and the midwives at Access Midwives (represented by Tamara Youngberg, Stoney Creek, Ontario, Canada) and Dr. Mark Oremus.

\section{Funding}

VH is supported by the Canadian Institutes of Health Research (FRN\#-336515), David L Sackett Scholarship, and Ashbaugh Graduate Scholarship. SDM is supported by a Tier II Canada Research Chair. None of the funding sources had any involvement in the study design, data collection, analysis, interpretation of data, writing of the report, or in the decision to submit the study findings for publication.

\section{Availability of data and materials}

The dataset generated and analysed during the current study is not publicly available because our institutional Research Ethics Board has not approved sharing of the dataset nor have we received approval from respondents to do so.

\section{Authors' contributions}

The conception and design of the study were developed by V.H. and S.M. The collection of data was conducted by V.H. The analysis and interpretation of the data were conducted by V.H. and S.M. The article was drafted and approved for submission by V.H. and S.M.

\section{Competing interests}

The authors declare that they have no competing interests.

\section{Consent for publication}

Not Applicable.

\section{Ethics approval and consent to participate}

The Hamilton Health Sciences/McMaster University granted Research Ethics Board approved this study prior to commencement (Reference Number: 2015-0459-GRA). Consent to participate was indicated by completion and submission of the questionnaire.

\section{Author details}

${ }^{1}$ Department of Health Research Methods, Evidence, and Impact, McMaster University, Hamilton, ON, Canada. ${ }^{2}$ Department of Obstetrics \& Gynecology, McMaster University, Hamilton, ON, Canada. ${ }^{3}$ Department of Radiology, McMaster University, Hamilton, ON, Canada. 
Received: 13 October 2016 Accepted: 6 January 2017

\section{Published online: 31 January 2017}

\section{References}

1. Statistics Canada. Leading Causes of Death in Canada, 2009. http://www. statcan.gc.ca/pub/84-215-x/2012001/tbl/t011-eng.htm. Accessed 10 Jan 2017.

2. Lawn JE, Cousens S, Zupan J. 4 million neonatal deaths: when? where? Why? Lancet. 2005;365(9462):891-900.

3. Mwaniki MK, Atieno M, Lawn JE, Newton CR. Long-term neurodevelopmental outcomes after intrauterine and neonatal insults: a systematic review. Lancet. 2012;379(9814):445-52.

4. Eutrope J, Thierry A, Lempp F, Aupetit L, Saad S, Dodane C, Bednarek N, De Mare L, Sibertin-Blanc D, Nezelof $S$, et al. Emotional reactions of mothers facing premature births: study of 100 mother-infant dyads 32 gestational weeks. PLoS One. 2014;9(8):e104093.

5. Romero R, Nicolaides K, Conde-Agudelo A, Tabor A, O'Brien JM, Cetingoz E, Da Fonseca E, Creasy GW, Klein K, Rode L, et al. Vaginal progesterone in women with an asymptomatic sonographic short cervix in the midtrimester decreases preterm delivery and neonatal morbidity: a systematic review and metaanalysis of individual patient data. Am J Obstet Gynecol. 2012;206(2): 124 e121-119.

6. Rafael TJ, Berghella V, Alfirevic Z. Cervical stitch (cerclage) for preventing preterm birth in multiple pregnancy. Cochrane Database Syst Rev. 2014;9: CD009166.

7. Alfirevic Z, Stampalija T, Roberts D, Jorgensen AL. Cervical stitch (cerclage) for preventing preterm birth in singleton pregnancy. Cochrane Database Syst Rev. 2012:4:CD008991.

8. Abdel-Aleem H, Shaaban OM, Abdel-Aleem MA. Cervical pessary for preventing preterm birth. Cochrane Database Syst Rev. 2013;5:CD007873.

9. Alfirevic Z, Owen J, Carreras Moratonas E, Sharp AN, Szychowski JN, Goya M. Vaginal progesterone, cerclage or cervical pessary for preventing preterm birth in asymptomatic singleton pregnant women with a history of preterm birth and a sonographic short cervix. Ultrasound Obstet Gynecol. 2013;41:146-51.

10. Conde-Agudelo A, Romero R, Nicolaides K, Chaiworapongsa T, O'Brien JM, Cetingoz E, da Fonseca E, Creasy G, Soma-Pillay P, Fusey S, Cam C, Alfirevic Z, Hassan SS. Vaginal progesterone vs cervical cerclage for the prevention of preterm birth in women with a sonographic short cervix, previous preterm birth, and singleton gestation: a systematic review and indirect comparison metaanalysis. Am J Obstet Gynecol. 2013;208(42):e1-18.

11. Farine D, Mundle WR, Dodd J. The Use of Progesterone for Prevention of Preterm Birth. JOGC. 2008;30(1):67-71

12. Brown R, Gagnon R, Delisle MF. Cervical Insufficiency and Cervical Cerclage. J Obstet Gynaecol Can. 2013;35 (12):1115-1127.

13. lams JD, Romero R, Culhane JF, Goldenberg RL. Primary, secondary, and tertiary interventions to reduce the morbidity and mortality of preterm birth. Lancet. 2008;371(9607):164-75.

14. Bailit JL, Berkowitz R, Thorp JM, Cleary K, Hartmann KE, Mercer BM. Use of progesterone to prevent preterm birth at a tertiary care center. J Reprod Med. 2007:52(4):280-4.

15. Lim AC, Goossens A, Ravelli AC, Boer K, Bruinse HW, Mol BW. Use of progesterone treatment for the prevention of recurrent preterm birth: identification of obstacles to change. Am J Perinatol. 2010;27(3):241-9.

16. Turitz AL, Bastek JA, Purisch SE, Elovitz MA, Levine LD. Patient characteristics associated with 17-alpha hydroxyprogesterone caproate use among a highrisk cohort. Am J Obstet Gynecol. 2016;214(4):536.e1-5.

17. Crane SS, Naples R, Grand CK, Friebert S, McNinch NL, Kantak A, Rossi E, McBride J. Assessment of adherence to guidelines for using progesterone to prevent recurrent preterm birth. J Matern Fetal Neonatal Med. 2016;29(11):1861-5.

18. Israfil-Bayli F, Toozs-Hobson P, Lees C, Slack M, Daniels J, Vince A, Ismail KM. Cervical cerclage and type of suture material: a survey of UK consultants' practice. J Matern Fetal Neonatal Med. 2014;27(15):1584-8.

19. Dodd JM, Ashwood P, Flenady V, Jenkins-Manning S, Cincotta R, Crowther CA. A survey of clinician and patient attitudes towards the use of progesterone for women at risk of preterm birth. Aust N Z J Obstet Gynaecol. 2007;47(2):106-9.

20. Henderson ZT, Power ML, Berghella V, Lackritz EM, Schulkin J. Attitudes and practices regarding use of progesterone to prevent preterm births. Am J Perinatol. 2009;26(7):529-36.
21. Hui D, Liu G, Kavuma E, Hewson SA, McKay D, Hannah ME. Preterm labour and birth: a survey of clinical practice regarding use of tocolytics, antenatal corticosteroids, and progesterone. JOGC. 2007;29(2):117-30.

22. Ness A, Dias T, Damus K, Burd I, Berghella V. Impact of the recent randomized trials on the use of progesterone to prevent preterm birth: a 2005 follow-up survey. Am J Obstet Gynecol. 2006;195(4):1174-9.

23. Ness A, Baxter J, Hyslop T, Berghella V. Progesterone for preventing premature birth: practice patterns of board-certified maternal-fetal medicine specialists in the united states. J Reprod Med. 2006;51(5):411-5.

24. Bousleiman SZ, Rice MM, Moss J, Todd A, Rincon M, Mallett G, Milluzzi C, Allard D, Dorman K, Ortiz F, et al. Use and attitudes of obstetricians toward 3 high-risk interventions in MFMU network hospitals. Am J Obstet Gynecol. 2015;213(3):398 e391-311.

25. Harrison MJ, Kushner KE, Benzies K, Rempel G, Kimak C. Women's satisfaction with their involvement in health care decisions during a highrisk pregnancy. Birth. 2003;30(2):109-15.

26. Sawyer A, Rabe H, Abbott J, Gyte G, Duley L, Ayers S. Parents' experiences and satisfaction with care during the birth of their very preterm baby: a qualitative study. BJOG. 2013;120(5):637-43.

27. Dillman DA, Smyth JD, Christian LM. Internet, mail, and mixed-mode surveys. The tailored design method. Hoboken: Wiley; 2003. Print.

28. Kelley K, Clark B, Brown V, Sitzia J. Good practice in the conduct and reporting of survey research. Int J Qual Health Care. 2003;15(3):261-6.

29. Ross S, Milne J, Dwinnell S, Tang S, Wood S. Is it possible to estimate the minimal clinically important treatment effect needed to change practice in preterm birth prevention? results of an obstetrician survey used to support the design of a trial. BMC Med Res Methodol. 2012;12:31.

30. Anand SS, Razak F, Davis AD, Jacobs R, Vuksan V, Teo K, Yusuf S. Social disadvantage and cardiovascular disease: development of an index and analysis of age, sex, and ethnicity effects. Int J Epidemiol. 2006;35(5):1239-45.

31. McDonald TP, Coburn AF. Predictors of prenatal care utilization. Soc Sci Med. 1988;27(2):167-72.

32. Higgins $P$, Murray ML, Williams EM. Self-esteem, social support, and satisfaction differences in women with adequate and inadequate prenatal care. Birth. 1994;21(1):26-33.

33. Say R, Murtagh M, Thomson R. Patients' preference for involvement in medical decision making: a narrative review. Patient Educ Couns. 2006;60(2):102-14.

34. Zupancic JA, Kirpalani H, Barrett J, Stewart S, Gafni A, Streiner D, Beecroft ML, Smith P. Characterising doctor-parent communication in counselling for impending preterm delivery. Arch Dis Child Fetal Neonatal Ed. 2002;87(2): F113-117.

\section{Submit your next manuscript to BioMed Central and we will help you at every step:}

- We accept pre-submission inquiries

- Our selector tool helps you to find the most relevant journal

- We provide round the clock customer support

- Convenient online submission

- Thorough peer review

- Inclusion in PubMed and all major indexing services

- Maximum visibility for your research

Submit your manuscript at www biomedcentral.com/submit
C) BioMed Central 